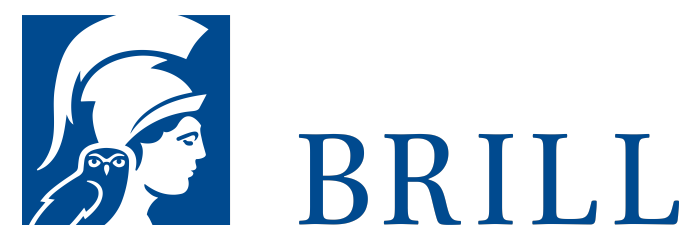

\title{
Schelling und die bildende Kunst
}

Zum Verhältnis von kunstphilosophischen System und konkreter Werkkenntnis

Authors: Arne Zerbst and Arne Zerbst

Schellings Kunstphilosophie wird erst lebendig durch die Beispiele der bildenden Kunst. Erstmals rückt deshalb Arne Zerbst neben der philosophischen auch die kunstgeschichtliche Dimension umfassend in den Blick.

Erst aus dem Gedanken der hierarchischen Gleichsetzung von Philosophie und Kunst kann ein Werk der Kunstphilosophie erwachsen, welches diese Gleichheit umzusetzen willens und in der Lage ist. Die Gleichberechtigung von Philosophie und Kunst nimmt folglich auch diese Studie in die interdisziplinäre Pflicht, dem die Ästhetik grundsätzlich bestimmenden Verhältnis von konkreter Werkkenntnis und philosophischer Systematik am Beispiel Schellings nachzuspüren.

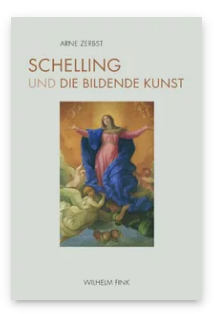

Pages: 440

Seiten, $113 \mathrm{~s} / \mathrm{w}$ Abb.

Language:

German

Subjects:

German

Idealism,

Philosophy

Publisher: Brill |

Fink

E-Book (PDF)

Released online:

o1 Feb 2012

ISBN: 978-3-

8467-5067-4

List price

USD $\$ 75.00$

Hardback

Publication date: 2o Jul 2011

ISBN: 978-3-

7705-5067-8

List price

USD $\$ 75.00$ 
For more information see brill.com

Order information: Order online at brill.com +44330 333 0049 | customerservices@brill.com Submission information: brill.com/authors

Titles published by Brill | Fink, Brill | mentis or Brill | Schöningh: +49(o)715413279216| brill@brocom.de 